\title{
Os desafios da Universidade nos dias atuais e os 40 anos da Pós-graduação da EEFE-USP
}

http://dx.doi.org/10.11606/1807-55092017000nesp019

António Teixeira MARQUES*

*Faculdade de Desporto, Universidade do Porto, Porto, Portugal.

\section{Universidade em transformação}

Num tempo de extraordinárias mudanças económicas e demográficas, a Educação Superior tem hoje um significado muito diferente do que tinha meio século antes. Na origem destas alterações está a transição económica de uma sociedade largamente baseada na agricultura para uma sociedade industrial e, mais contemporaneamente, para uma economia de serviços pós-industrial ${ }^{1}$. Neste contexto, a revolução científica e tecnológica está a abrir novas possibilidades de desenvolvimento nas sociedades, uma classe média crescente está a criar uma demanda sem precedentes no acesso à educaçáo superior, e os modelos de financiamento do ensino superior - tidos por seguros durante décadas - começam a ser postos em causa ${ }^{2}$.

Também as economias emergentes, em desenvolvimento, têm vindo a colocar a educação no centro das suas prioridades, com repercussão na expansão dos sistemas de ensino superior e numa mobilidade acrescida de estudantes internacionais. $\mathrm{O}$ desejo de prosperidade por parte dos estudantes e a procura de conhecimentos e competências mais avançados nos locais de trabalho são fatores que se combinaram para fazer da mobilidade de estudantes de pós-graduação um fenómeno digno de estudo ${ }^{3}$. Como referiu KNIGHT ${ }^{4}$, a internacionalização está a mudar o mundo do ensino superior e a globalização está a mudar o mundo da internacionalização, com esta a tornar-se central à missão das universidades e a assumir uma dimensão mais sistémica e não apenas centrada na mobilidade.

Nos últimos 10 anos mudou muito a internacionalização do ensino superior, e esta mudança tem vindo a evoluir de um modelo mais cooperativo para um modelo mais competitivo ${ }^{5} \mathrm{e}$ a caracterizar-se por uma competiçấo mundial, não apenas entre os sistemas de ensino superior, mas também entre as próprias Instituições de Ensino Superior (IES) ${ }^{6}$. Nesta competição, um esforço importante é consagrado à atração de estudantes e investigadores com talento, pois deles dependem a possibilidade de desenvolvimento de projetos científicos e os financiamentos que lhe estão associados e, também, a melhoria de posições nos "rankings" internacionais de universidades.

Resultados de alguns estudos ${ }^{7}$ têm mostrado, igualmente, que quanto maior é o número de estudantes que atinge qualificaçóes superiores, maior é a procura por níveis de educação mais avançados. De facto, subjacente ao crescimento do número de estudantes de pós-graduação está a massificaçáo do ensino superior, a qual tem possibilitado a uma populaçáo cada vez mais vasta uma educação que vai além do primeiro ciclo (ou grau) de ensino. À medida que o mundo se torna mais competitivo e as economias mais integradas, há evidência de que o primeiro grau de formação já não é suficiente e se faz necessário investir em qualificaçóes mais elevadas ${ }^{8}$. Esta tendência já não traduz, apenas, a vontade de cada indivíduo de procura de melhores oportunidades de emprego, mas também o esforço coordenado dos governos de muitos países de criação de forças de trabalho altamente competentes. Com efeito, a especulação sobre as razóes pelas quais a educação pós-graduada se tornou um tema central na agenda dos governos e das universidades apoia-se na crença de que a economia do conhecimento do Séc. XXI requer trabalhadores com conhecimentos avançados, capazes de resolver problemas complexos usando competências intelectuais e analíticas sofisticadas?. Uma economia com postos de trabalho de um tipo novo que exigirão tarefas menos rotineiras, mais complexas e, também, mais exigentes ${ }^{10}$. 


\section{Crescimento da oferta pós-graduada}

Durante muitos anos, a necessidade de uma formação avançada obrigou muitos de nós a procurar essa formação em universidades e centros de pesquisa de países onde os sistemas de ensino superior, científicos e tecnológicos estavam mais desenvolvidos. Hoje, um número cada vez maior de IES responde a este desafio com uma aposta na formação pós-graduada, na ciência e na tecnologia, que tem permitido fazer essa capacitaçáo de recursos dentro dos próprios países.

A formação pós-graduada ganhou uma dimensão muito importante na atividade das universidades nas últimas décadas. Este crescimento surge associado a uma universidade em transformaçáo, uma universidade que não é já, apenas, uma instituição de transmissão de saber para se constituir cada vez mais como um centro de produção do conhecimento, um centro de pesquisa científica e tecnológica. Na Europa, o Processo de Bolonha - com a estruturação das formaçóes universitárias em três ciclos de ensino, a redução do número de anos de formação pré-graduada, e a mudança de orientação sobre os objetivos da formação inicial - veio a determinar uma procura crescente pelas formaçóes pós-graduadas.

A expansão da formação pós-graduada trouxe, também, grandes desafios às IES ${ }^{9}$ : a transformação de sistemas de elite em sistemas massificados; as dificuldades de financiamento de uma formação pósgraduada em acelerado crescimento; a necessidade de equilíbrio entre o número crescente de estudantes, no acesso, com expectativas de realizaçáo do seu potencial humano e a qualidade das formaçóes; a necessidade de assegurar a qualidade e reputação dos programas de formaçáo num mundo cada vez mais competitivo; a enorme diversidade de estudantes e de programas de pós-graduação.

Antes marcadamente elitista, a educação superior está a massificar-se e com a massificação cresceu também o número de estudantes que procuram adquirir na formação pós-graduada os conhecimentos científicos e as competências técnicas e profissionais que a formação pré-graduada não lhes proporcionou. Porém, isto não se faz sem custos para os estudantes e as respectivas famílias. De facto, um número crescente de países tem vindo a passar para os estudantes uma parte substancial dos custos de formação, obrigando muitos estudantes a trabalhar para suportar estes custos e, como consequência, resultando num aumento da duraçấo dos cursos e das taxas de abandono e na diminuição da qualidade ${ }^{2,9}$.

O que diferencia, no essencial, uma formação pós-graduada de uma formação pré-graduada? Por um lado, o âmbito dos estudos na formação pós-graduada é mais reduzido e concentrado. Por outro lado, o nível de exigências e as expectativas com a quantidade e a qualidade do trabalho dos estudantes são maiores. Assim, nos programas de pós-graduação: os estudos orientam-se para uma área específica; os procedimentos de recrutamento de estudantes são mais seletivos; os programas de formação incluem atividades de ensino, pesquisa e estágios profissionais; as turmas são mais reduzidas e é maior a interação com os estudantes; a avaliaçáo do trabalho dos estudantes pelos professores e pelos pares é mais rigorosa.

\section{Reorganização da formação pós-graduada}

Tradicionalmente, a formação pós-graduada era essencialmente académica e tinha como objetivo promover o desenvolvimento de uma pesquisa original numa área de estudos. No presente é, também, orientada para o desenvolvimento de conhecimentos e competências para o exercício de uma profissão específica.

Esta questão marcou o debate em alguns países, onde, até há pouco tempo, largos setores das universidades se opunham a uma pós-graduação profissionalizante. Hoje, setores profissionais em alguns dos países mais desenvolvidos do mundo estáo a estabelecer critérios para o recrutamento de recursos humanos já ao nível de doutor e a colaborar com as universidades em programas de capacitaçáo de pós-graduados que incluem o estágio em empresas.

Num cada vez maior número de países existe uma oferta de pós-graduação que considera modelos de formaçáo distintos: orientados para o ensino (semelhantes aos primeiros ciclos, 
mas de nível mais avançado ou numa área mais especializada) e orientados para a pesquisa (preparaçáo dos doutorados); de orientaçáo vocacional (profissionalizante) e de orientação não vocacional (académica).

A própria organização dos cursos denuncia preocupação com a resposta aos desafios das sociedades. Conscientes de que a fertilização cruzada entre as disciplinas alimenta o pensamento no mundo contemporâneo e deve, por isso, aparecer refletida na educação doutoral ${ }^{11}$, um cada vez maior número de países valoriza a pesquisa interdisciplinar em programas doutorais que transcendem as fronteiras disciplinares e integram estudantes com diferentes "backgrounds" científicos". Esta concentração de recursos em programas de doutorado transversais (resultantes de processos de reorganização de pequenos programas de doutorado de perfil disciplinar) pretende promover a criaçáo de diversidade e massa críticas na educação doutoral ${ }^{12}$ e oferecer aos estudantes a possibilidade de alargar os seus horizontes científicos.

A introduçáo formal de uma formação doutoral estruturada em programas adquiriu grande importância na Europa e o percurso que conduz ao doutorado já não se circunscreve à elaboração de uma tese, antes

\section{A questão da qualidade}

Pode a pós-graduação ser massificada sem pôr em causa a qualidade? Não devem os cursos de pós-graduação, pela sua própria natureza, implicar uma rigorosa seleção que se apoie em requisitos de admissão, tanto mais exigentes, quanto mais alto é o padrão da universidade? Estarão todos os estudantes que concluem a sua formaçáo inicial (independentemente do seu interesse) preparados para uma especialização aprofundada e uma formação científica avançada?

Há especialistas ${ }^{2}$ que pensam ser próprio dos sistemas em expansão que o alargamento do ensino superior resulte numa diminuição da qualidade da educação. Por um lado, porque o alargamento do universo na procura se faz acompanhar por uma diminuição dos níveis de preparação dos candidatos ao ensino superior; e, por outro, porque com a expansão é mais difícil reunir os recursos docentes em quantidade suficiente para assegurar essa qualidade. inclui a frequência de um programa de estudos estruturado em disciplinas. A própria tese pode integrar artigos publicados durante a formação pós-graduada? .

Nos últimos 10-15 anos as IES investiram esforços e recursos consideráveis na melhoria dos ambientes da pesquisa doutoral: criando escolas doutorais (ou de pós-graduação); introduzindo disciplinas e programas de seminários como parte da formaçáo doutoral; oferecendo aos estudantes a oportunidade de discutir os seus projetos com outros estudantes de pesquisa; e fazendo um grande investimento financeiro para a formação de competências profissionais? .

De facto, o doutorado - antes uma qualificação para uma carreira académica - é hoje entendido pelas universidades e entidades empregadoras como uma qualificaçáo de alto nível que prepara as pessoas para pensar de uma forma profunda e rigorosa acerca de um assunto e traduzir este conhecimento em novas oportunidades para a sociedade ${ }^{11}$. Doutorados profissionalizantes já têm lugar, por exemplo, no mundo anglo-saxônico em países como o Reino Unido, os USA, ou a Austrália ${ }^{9}$, e na Alemanha as capacitaçóes de doutorado são cada vez mais uma exigência nas entrevistas para o recrutamento de altos lugares em empresas ou em outras instituiçóes.

Mas, há também quem pense que o forte crescimento dos números dos estudantes de mestrado em quase todos os países levanta sérias preocupaçóes com a qualidade e com o potencial impacto que a sua diminuição pode ter nos programas doutorais e na própria preparação para o mundo do trabalho. Neste sentido, a LERU (League of European Research Universities) defende que os programas de pósgraduação devem ser mais do que, apenas, treinar pessoas para ir para o mundo do trabalho, e que é o talento, mais do que a tecnologia, o que a sociedade e as empresas necessitam das universidades?.

Com a pressão da globalização, a forte competição nacional e internacional, e a crescente mobilidade de estudantes, não é surpresa que um número crescente de países dedique uma particular atenção às questôes da qualidade. Isto tem vindo a ser feito através: a) da adopção de instrumentos institucionais que garantam a qualidade académica; b) da criaçáo de quadros de referência para as qualificaçôes; c) da 
definição de padróes de qualificação dos estudantes no acesso; d) de um acompanhamento mais cuidado dos percursos dos estudantes durante as formaçóes pós-graduadas; e e) de uma forte posta na internacionalização dos programas.

Nas IES do Reino Unido, os programas de pesquisa pós-graduada têm vindo a instituir um "Código de Prática", o qual integra um conjunto de documentos e instrumentos que procuram garantir a qualidade académica e as orientaçôes definidas para as IES pela Agência para a Garantia de Qualidade no Ensino Superior (QAAHE). Este Código assume que cada IES deve dispor de sistemas próprios que permitam, através de uma verificação independente, avaliar a qualidade, as orientaçôes e princípios que promove, e a efetividade dos seus sistemas de garantia de qualidade ${ }^{13}$. Este Código integra por isso secçóes estruturadas numa série de preceitos, princípios e explicaçóes que a comunidade universitária e científica identificou como importantes para a garantia da qualidade e dos padróes académicos. Cada IES deve ser capaz de demonstrar que os aspectos que decorrem dos preceitos estão a ser resolvidos por elas, através dos seus processos organizativos e de gestáo. E, por isso, o Código resulta numa afirmação de boas práticas que foi endossada às IES pela comunidade universitária ${ }^{13}$.

Nas suas diferentes secçóes o código prevê preceitos que procuram enquadrar aspectos como: procedimentos institucionais; ambiente de pesquisa (por exemplo, as IES só poderão aceitar estudantes de pesquisa se disponibilizarem um ambiente que proporcione apoio e aprendizagem sobre pesquisa e no qual esteja a ocorrer pesquisa de elevada qualidade); seleção e admissão de estudantes (por exemplo, só estudantes devidamente preparados e qualificados serâo admitidos nos programas de pesquisa); supervisão (por exemplo, as IES assegurarão que a qualidade da supervisão não é posta em risco em resultado de um excessivo volume de responsabilidades atribuído a cada supervisor); procedimentos de monitorizaçáo do progresso dos estudantes; desenvolvimento da pesquisa e de outras competências (por exemplo, as necessidades de desenvolvimento de cada estudante serão identificadas e acordadas conjuntamente pelo estudante e o "staff" académico); mecanismos de "feedback", por parte da IES, em resposta a todos aqueles que de alguma forma estão envolvidos nos programas de pesquisa pósgraduados; avaliação (por exemplo, critérios claros e compreensíveis para estudantes, "staff" académico e examinadores externos); instrumentos para assegurar a representaçáo dos estudantes e tratar com estes de assuntos do seu interesse; queixas e apelos ${ }^{13}$.

$\mathrm{Na}$ Europa, estão a ser criados quadros de referência para as qualificaçôes em que participam todos os países europeus, promovendo desta forma uma convergência nestas políticas. Estes quadros de referência visam garantir a qualidade e proporcionar indicadores de comparabilidade e, desta forma, facilitar a mobilidade de estudantes e o reconhecimento das formaçóes.

Uma preocupação comum centra-se nos padrōes de qualificação dos estudantes à entrada, por forma a evitar que a expansão dos números no acesso prejudique a qualidade dos que entram nas formações pós-graduadas. Um cada vez maior número de países utiliza procedimentos de avaliação dos candidatos às pós-graduaçóes em ciência como um modo de assegurar que estes estudantes dispóem do potencial para serem bem sucedidos. Muitos países procuram, também, assegurar que os candidatos aos programas de pós-graduação têm boas competências linguísticas (particularmente em inglês), e que todos aqueles que têm as capacidades e qualidades para obter sucesso, mas não têm disponibilidades financeiras para custear as suas formaçóes, não sejam condicionados no acesso. Porém a remoçáo de barreiras representadas pelos constrangimentos financeiros tem sido lenta?

A monitorização do progresso dos estudantes durante a formação pós-graduada é também uma preocupação. O que é que as IES estáo a fazer, não apenas para atrair os melhores estudantes, mas também para corresponder às suas expectativas de formação? Que estratégias estão as escolas de pósgraduação a desenvolver para melhorar a experiência e a qualidade das realizaçóes dos estudantes durante os anos da sua formação?

Estas são questôes para as quais procuram respostas muitas universidades, promovendo iniciativas inovadoras, criando ambientes favoráveis de trabalho, e encorajando os professores a ouvir os seus estudantes e a dar-lhes a ajuda de que eles precisam nas diferentes fases da sua pós-graduação e nas suas futuras carreiras, por exemplo ${ }^{14}:$ a) apoiandoos na aquisição e aperfeiçoamento de competências linguísticas; b) organizando cursos de curta duração orientados para as respostas aos problemas dos estudantes - como escrever um artigo científico, como decorre o processo de publicação científica, como utilizar as suas competências em atividades de consultoria...; c) oferecendo programas com 
"blended learning" e "virtual learning", procurando ajustar a formação, de forma flexível, às conveniências dos estudantes; $\mathrm{d}$ ) recrutando académicos experientes como mentores dos estudantes; e) melhorando a formação dos supervisores; f) oferecendo aos estudantes ambientes de trabalho estimulantes e oportunidades de participação em redes científicas.

Estes dois últimos aspectos são considerados cruciais por muitos especialistas. A qualidade do trabalho de supervisão e o próprio acesso à supervisão não são considerados satisfatórios por muitos estudantes de pós-graduação. Esforços para melhorar a formação de supervisores estão, por isso, no centro das preocupaçóes de muitas universidades ${ }^{12}$. No que se refere às redes colaborativas, uma vez que expóem os estudantes a contatos com especialistas internacionais e a uma potencial interação com um vasto número de investigadores, essas redes criam ambientes de pesquisa muito estimulantes que asseguram condiçóes de grande sucesso na educação pós-graduada'. Este aspecto é particularmente relevante na educação doutoral, que deve estar embebida num forte ambiente e cultura de pesquisa científica para assegurar que as oportunidades de fertilização cruzada entre disciplinas possam promover a necessária interdisciplinaridade. Por esta razão, acredita-se que a educação doutoral é melhor desenvolvida em instituiçóes de pesquisa intensiva ou integrada em parcerias, onde os benefícios de um largo espectro de atividades de pesquisa possam ser explorados ${ }^{11}$. Complementarmente, muitas universidades estão ainda a oferecer aos graduados competências pessoais e profissionais na área da gestão, como parte da sua experiência doutoral ${ }^{11}$.

Quase todos os governos do mundo estão a fazer esforços para internacionalizar os seus sistemas de ensino superior, associando a colaboração internacional aos processos de melhoria de qualidade da educação. As IES, as agências de acreditação, e as agências de financiamento esperam que do processo de internacionalização e da colaboração com outras IES resultem programas mais fortes e um avanço na qualidade das formaçóes. Procuram, desta forma, promover sinergias entre as instituiçóes ${ }^{15}$ e alimentar relaçóes pessoais que são cruciais para o sucesso de longo prazo numa economia global cada vez mais aberta.

Nos últimos anos, um elevado número de IES está já a operar internacionalmente num processo que envolve a criação de parcerias entre instituiçóes e inclui a criação de programas pósgraduados conjuntos ou em associação. Estes esforços têm sido limitados em muitos países por obstáculos associados ao enquadramento jurídico da colaboração internacional na criação de programas pós-graduados. As universidades que vão mais à frente são aquelas que estão a encontrar soluçóes mais rápidas para os problemas, superando os constrangimentos de ordem jurídica e normativa que as próprias legislaçôes nacionais estabelecem à criaçáo de graus conjuntos ou ao reconhecimento de graus em colaboração internacional.

Uma economia global baseada no conhecimento, vai também forçar uma maior atenção à “internacionalização do curriculum”, uma vez que o conhecimento e as competências de todos os graduados têm de refletir que eles estão aptos a operar num mundo e num mercado de trabalho cada vez mais aberto. Um currículo que proporcione conhecimento e competências internacionais e interculturais, com o objetivo de preparar (profissional, social e emocionalmente) os estudantes para o seu desempenho num contexto internacional e multicultural ${ }^{16}$. De facto, numa economia global, não faz sentido orientar as qualificaçóes dos estudantes apenas para as necessidades dos mercados de trabalho locais. Por outro lado, se as universidades devem preparar os estudantes para as necessidades dos mercados internacionais, também os currículos necessitam de ser internacionalizados. E uma parte dessas qualificaçóes e competências devem, não apenas ser "internacionais", mas também "interculturais".

Este movimento de internacionalização do currículo começa a ter já importância em países do norte da Europa, como a Dinamarca, a Finlândia, a Noruega e Suécia ${ }^{17}$.

Uma cada vez maior e melhor integração entre as formações de mestrado, de doutorado e de pósdoutorado corresponde, também, a uma orientação com grande acolhimento internacional ${ }^{12}$.

Os "post-docs" (também considerados os $\mathrm{PhD}+$ ) tornaram-se elementos chave da força de trabalho universitária, a sua parte mais barata e um meio disponível para aumentar a produtividade académica. O seu número está a crescer rapidamente, prevendose que, dentro de uma década, possa existir mais de um milhão em todo mundo, em resultado do cada vez maior número de graduados com doutorado ${ }^{18}$.

O primeiro Forum Humboldt sobre as perspectivas de carreira pós-doutoral, realizado em Washington em $2007^{18}$, constatou que: os indivíduos com muito talento têm agora uma elevada mobilidade; os países estão a implementar de forma crescente medidas políticas para atrair investigadores estrangeiros $\mathrm{e}$ 
expatriados e a concentrar o seu investimento em potencial para a pesquisa (talento + instalações e equipamento + redes); há um aumento nos fluxos de retorno aos países de origem dos investigadores treinados no estrangeiro; as assimetrias de poder entre os países podem desequilibrar (em favor dos países com mais poder) a mobilidade dos talentos;

\section{Considerações finais}

A sociedade está a mudar de uma forma muito célere e estão a aumentar as incertezas e os desafios que acompanham os períodos de mudança.

Também as universidades estão a mudar. Saíram das torres de marfim, num processo de aprendizagem não isento de dúvidas, de hesitaçôes e de riscos, e acrescentaram às suas missóes tradicionais - o ensino e a pesquisa - uma terceira missão - a abertura à sociedade. E têm-no feito num quadro de convulsão interna mais ou menos acentuado, onde coexistem posiçóes conservadoras, reativas à mudança, e posiçôes mais favoráveis às dinâmicas de progresso.

A massificação do ensino superior é uma consequência dessas mudanças. Com o aumento do número de candidatos à formação pré-graduada, aumentou também o número de estudantes que centenas de companhias que operam a nível global estão a oferecer posiçôes de "postdoc" em laboratórios bem equipados, com condiçóes atrativas e boas perspectivas de carreira, competindo diretamente com as universidades no mercado dos talentos; a mobilidade não substitui o desenvolvimento da capacidade de pesquisa a um nível local ou nacional.

procuram aceder a níveis mais avançados de educação superior na sociedade do conhecimento.

E se a massificaçáo do ensino superior tem vindo a pressionar fortemente a qualidade das formaçôes pós-graduadas oferecidas pelas universidades, é também cada vez mais claro que na sociedade global em que vivemos a competição irá acentuarse. E que, no futuro, dificilmente haverá lugar para instituições sem qualidade. Por isso, seja a oferta pós-graduada orientada para a pesquisa ou para o ensino, para a academia ou para o mundo de trabalho, os estudantes que estão a ser chamados a pagar a sua formação vão querer escolher, cada vez mais, instituiçôes de formação onde a excelência esteja no centro das preocupaçóes das IES, seja na pesquisa científica, seja na formação pós-graduada.

\section{Referências}

1. Börjesson M, Ahola S, Helland H, Thomsen J-P, editors. Enrolment patterns in Nordic higher education, ca 11945 to 2010: institutions, types of education and fields of study. Oslo: Nordic Institute for Studies in Innovation, Research and Education; 2014. (Working Paper 15/2014).

2. Gibney E. A different world. Times Higher Education 31 January 2013, published online at http://www.timeshighereducation.co.uk/features/a-different-world/2001128.article.

3. British Council. Postgraduate student mobility trends to 2024. UK: British Council; 2014. (Education Intelligence, Oct. 2014).

4. Knight J. Higher education in Turmoil: the changing world of internationalization. Rotterdam: Sense; 2008.

5. WIT H. Internationalisation of higher education in Europe and its assessment, trends and issues. Netherlands: NVAO Nederlands-Vlaamse Accreditatieorganisatie; 2010.

6. Wächter B. Internationalisation at home: the context. In: Crowther P, Joris M, Otten M, Nilsson B, Teekens H, Wächter B. Internationalisation at home: a position paper. Amsterdam: European Association for International Education; 2000. p.5-13.

7. British Council. Megatrends: the future of international education. London: British Council; 2013. (Education Intelligence, Nov. 2013).

8. Swain H. Postgrads: at last you're on the agenda. The Guardian. 2012 February 28. Available from: https://www.theguardian.com/education/2012/feb/28/postgraduates-on-the-government-agenda.

9. Clarke G, Lunt I. International comparisons in postgraduate education: quality, access and employment outcomes. London: University of Oxford: 2014. Report to Higher Education Funding Council for England, Sept. 2014. 
10. Cerejeira J, Portela M. Para que serve um mestrado? Jornal "Público". 10 abr. 2017.

11. Bogle D, Dron M, Eggermont J, van Henten JW. Doctoral degrees beyond 2010: training talented researchers for society. Leuven: League of European Research Universities; 2010. Report March 2010.

12. Thune T, Kyvik S, Sörlin S, Olsen TB, Vabø A, Tømte C. PhD education in a knowledge society: an evaluation of PhD education in Norway. Oslo: Nordic Institute for Studies in Innovation, Research and Education; 2012. Report 25/2012.

13. Quality Assurance Agency for Higher Education. Code of practice for the assurance of academic quality and standards in higher education. London: QAAHE; 2004. (Section 1: postgraduate research programmes, Sept. 2004).

14. Whitehead F. What are universities doing to improve the HE experience for postgraduates? The Guardian. $2012 \mathrm{Fe}-$ bruary 28. Available from: https://www.theguardian.com/higher-education-network/blog/2012/feb/28/postgraduatestudent-experience.

15. Foreign Affairs, Trade and Development Canada. Canada's international education strategy: harnessing our knowledge advantage to drive innovation and prosperity. Ottawa: Government of Canada; 2014.

16. Nilsson B. Internationalising the curriculum. In: Crowther P, Joris M, Otten M, Nilsson B, Teekens H, Wächter B. Internationalisation at home. a position paper. Amsterdam: European Association for International Education; 2000. p.21-7.

17. Beelen J. Internationalisation at home in a global perspective: a critical survey of the 3rd Global Survey Report of IAU. Int J Educ Higher Educ. 2011;8:249-64.

18. Gallagher M. Postdocs and changing researcher career paths. In Schwarz H, Chen P. Postdoctoral career paths 2.0: the golden triangle of competitive junior investigators, adequate academic systems, and successful careers. Berlin: Dr. Josef Raabe Verlags-GmbH; 2013. p. 6-16. (Proceedings of the 7th Forum on the Internationalization of Sciences and Humanities).

\author{
ENDEREÇO \\ António Teixeira Marques \\ Faculdade de Desporto \\ Universidade do Porto \\ R. Dr. Plácido Costa, 91 \\ 4200-450 - Porto - PORTUGAL \\ e-mail: amarques@fade.up.pt
}

